\title{
Impacts of Diatomaceous Earth on the Properties of Cement Pastes
}

\author{
Hasanzadeh B.*, Sun Z.
}

Dept. of Civil and Environmental Engineering, Univ. of Louisville, Louisville, KY 40292.

* Corresponding Author: bashir.hasanzadeh@louisville.edu

Received: 10-05-2018

Revised: 02-10-2018

Accepted: 19-10-2018

\begin{abstract}
Fresh properties of concrete are closely related to operation and construction, such as transporting, placing, compacting, etc.; and they also have a great impact on the lifetime performance of concrete. In this paper, the influence of Diatomaceous Earth (DE) as a natural pozzolan on fresh properties of cement pastes has been investigated. Cement pastes with different water-to-binder ratios $(\mathrm{w} / \mathrm{b}=0.4,0.5$ and 0.6$)$ and $0 \%, 2 \%, 6 \%$ and $10 \%$ replacement levels of DE by weight of cement were studied. Viscosity, yield stress, flow diameter, bleeding, setting times, and the heat evolution of all cement pastes were measured. Results showed that DE has a significant impact on fresh properties of cement pastes. Increasing DE content in cement pastes resulted in higher viscosity and lower flow diameters. Pastes with higher DE replacement levels showed lower bleeding rate and shorter initial and final setting times. The isothermal calorimetry test also showed that, as a pozzolanic material, DE lowered the heat of hydration, however, it advanced the appearance of the heat evolution peaks which was in agreement with the results from setting time tests.
\end{abstract}

Key words: Fresh properties, diatomaceous earth, rheology, isothermal calorimetry, setting time, bleeding.

\section{Introduction}

Diatomaceous Earth (DE), also known as Kieselguhr, is a chalk-like, soft, very fine-grained, earthy, and siliceous sedimentary material (Robert \& Crangle, 2013). It is finely porous, less in density, and essentially chemically inert with low thermal conductivity (Robert \& Crangle, 2013; Bakr, 2010). DE consists of amorphous hydrous silica cell walls of dead diatoms (opal, $\mathrm{SiO}_{2} \bullet \mathrm{nH}_{2} \mathrm{O}$ ), which are microscopic single-cell aquatic plants (algae). The diatom cells contain an internal, elaborate siliceous skeleton consisting of two valves (frustules), which fit together much like a pillbox (Dolley, 1999). These skeletons vary in size from less than $1 \mu \mathrm{m}$ to more than $1 \mathrm{~mm}$ but are typically from 10 to $200 \mu \mathrm{m}$ (Robert \& Crangle, 2013). There are many different types of DE but almost all commercial DEs are composed of around $80 \%$ to $90 \%$ silica $\left(\mathrm{SiO}_{2}\right)$ (Bakr, 2010; Miller et al., 2010; Jud Sierra et al., 2010).

United States' production of diatomite in 2015 was estimated to be 925,000 metric tons, which was more than $40 \%$ of the whole world's DE production (Jewell \& Kimball, 2016). There are wide ranges of applications for DE. In 2015 in the US, 55\% of diatomite was used in filter aids, $21 \%$ was used as cement additives, $14 \%$ was used as fillers, and $9 \%$ was used as absorbents. According to the United States Geology Surveys (USGS), using DE as a cement additive has increased significantly from $14 \%$ in 2014 to $21 \%$ in 2015 and now it is the second largest DE consumption in the US (Jewell \& Kimball, 2016 ; Jewell \& Kimball, 2015).

DE has been used thousands of years ago, as an addition to lime for binding limestone aggregates together in ancient Egypt pyramids, to more recent years as a natural pozzolanic additive for concrete (Miller et al., 2010; Jud Sierra et al., 2010). It is believed that replacing Portland cement with DE to some level can improve some properties of concrete. 
Being different from other commonly used pozzolanic materials, such as fly ash, silica fume, and slag, that have had more research conducted to investigate their influences on concrete properties, much less researches have been reported on the application of DE in concrete. In recent years, due to the increased usage of DE as a cement additive, some researches focused on mechanical properties have been reported (Aydin \& Gül, 2007; Degirmenci \& Yilmaz, 2009; Ergün, 2011; Fragoulis et al., 2005; Kastis et al., 2006; Stamatakis et al., 2003; Yılmaz \& Ediz, 2008). Separate studies by Ergun (2010), Fragoulis et al. (2005) and Stamatakis et al. (2003) on different types of diatomaceous earth showed that replacing cement by DE up to $10-15 \%$ increased compressive and flexural strength compared to control samples (almost at all different measured ages with highest increase at 10\%). They concluded that samples with higher content of reactive silica and a higher Blaine surface area showed a higher increase in compressive strength. Also, studies by Kastis et al. (2006) and Yilmaz and Ediz (2008) found that replacement levels up to $10 \%$ of cement content showed comparable compressive strength compared to the control samples, while samples with DE content higher than $10 \%$ showed a significant drop in strength. On the other hand, studies by Aydin and Gül (2007) and Degirmenci and Yilmaz (2009) showed that for all replacement levels and all measured ages, the module of elasticity and compressive and flexural strength were lower than those of the control samples. However, they found that using DE could improve both freeze-thaw durability and sulfate attack resistance. As these studies mainly focus on hardened properties of concrete, a comprehensive study on the impact of DE on fresh properties of concrete is lacking. Fresh properties of concrete, including setting, rheology, bleeding, and early hydration are closely related to operation and construction, such as transporting, placing, compacting, etc.; and they also have a great impact on the lifetime performance of concrete.

Therefore, this paper studies the influence of DE as a partial replacement of Portland cement on fresh properties of cement pastes. For this purpose, pastes with water-to-binder ratios (w/b) of $0.4,0.5$, and 0.6 were investigated. Based on the findings of the aforementioned studies, only replacement levels up to $10 \%$ were considered. Thus, for each $\mathrm{w} / \mathrm{b}$ ratio, three replacement levels of $2 \%, 6 \%$, and $10 \%$ of cement with DE were used. The influences of DE replacement on flowability, viscosity and yield stress, bleeding, setting time, and heat signature were studied systematically.

\section{Materials and experiment procedures}

\subsection{Raw Materials}

Ordinary Type I Portland cement (from CEMEX, Louisville plant (KY, USA)) was used in all the mixtures. The mean size of the cement particles was $11.4 \mu \mathrm{m}$, determined through a laser particle size analyzer. The Blaine surface area was $400.8 \mathrm{~m}^{2} / \mathrm{kg}$. The chemical compositions of this type I cement were measured with XRF and they are listed in Table 1. The mineral compositions for this cement are calculated based on the Bougue's equation (Taylor, 1997) and are provided in Table 2 .

Table 1. Chemical composition of type I portland cement and Diatomaceous Earth

\begin{tabular}{|c|c|c|}
\hline Compound (\%) & Type I Portland cement & Diatomaceous Earth \\
\hline \hline $\mathrm{SiO}_{2}$ & 19.70 & 93.5 \\
\hline $\mathrm{Al}_{2} \mathrm{O}_{3}$ & 4.84 & 1.6 \\
\hline $\mathrm{Fe}_{2} \mathrm{O}_{3}$ & 3.05 & 1.1 \\
\hline $\mathrm{CaO}$ & 62.62 & 0.4 \\
\hline $\mathrm{MgO}$ & 4.00 & 0.05 \\
\hline $\mathrm{SO}_{3}$ & 3.23 & 0.12 \\
\hline $\mathrm{Na}_{2} \mathrm{O}$ & 0.15 & 2.51 \\
\hline $\mathrm{K}_{2} \mathrm{O}$ & 0.49 & 0.09 \\
\hline $\mathrm{LO}$ & 1.21 & 0.35 \\
\hline
\end{tabular}


Table 2. Mineral composition of type I Portland cement

\begin{tabular}{|c|c|}
\hline Compound & Wight, $\%$ \\
\hline \hline $\mathrm{C}_{3} \mathrm{~S}$ & 59.1 \\
\hline $\mathrm{C}_{2} \mathrm{~S}$ & 11.9 \\
\hline $\mathrm{C}_{3} \mathrm{~A}$ & 7.67 \\
\hline $\mathrm{C}_{4} \mathrm{AF}$ & 9.3 \\
\hline
\end{tabular}

DE used in this study is a commercial pure diatomaceous earth, usually a powder, available widely on the market. The mean size of DE particles is $19 \mu \mathrm{m}$ based on a laser particle size analyzer and the Blaine surface area was $593 \mathrm{~m}^{2} / \mathrm{kg}$. The chemical composition of DE is also listed in Table 1.

\subsection{Mixing procedures and testing matrix}

The details of mix proportions are listed in Table 3, where "OPC" indicates control samples with ordinary type I cement only, and "D" indicates the pastes with DE replacement. Three w/b ratios of $0.4,0.5$, and 0.6 were used. For each $\mathrm{w} / \mathrm{b}$ ratio, three replacement levels of $\mathrm{DE}$ were studied.

Table 3. Mix proportions

\begin{tabular}{|c|c|c|c|c|c|}
\hline Cement paste & w/c & DE replacement level (\%) & Cement (gr) & DE (gr) & Water (gr) \\
\hline \hline OPC-0.4 & 0.4 & 0 & 700 & 0 & 280 \\
\hline D2-0.4 & 0.4 & 2 & 686 & 14 & 280 \\
\hline D6-0.4 & 0.4 & 6 & 658 & 42 & 280 \\
\hline D10-0.4 & 0.4 & 10 & 630 & 70 & 280 \\
\hline OPC-0.5 & 0.5 & 0 & 700 & 0 & 350 \\
\hline D2-0.5 & 0.5 & 2 & 686 & 14 & 350 \\
\hline D6-0.5 & 0.5 & 6 & 658 & 42 & 350 \\
\hline D10-0.5 & 0.5 & 10 & 630 & 70 & 350 \\
\hline OPC-0.6 & 0.6 & 0 & 700 & 0 & 420 \\
\hline D2-0.6 & 0.6 & 2 & 686 & 14 & 420 \\
\hline D6-0.6 & 0.6 & 6 & 658 & 42 & 420 \\
\hline D10-0.6 & 0.6 & 10 & 630 & 70 & 420 \\
\hline
\end{tabular}

When mixing the control pastes (OPC-0.4, OPC-0.5, and OPC-0.6), water was gradually added to the cement over the first minute of mixing and then mixing continued for two additional minutes at a low speed of $136 \mathrm{rpm}$. The sample was then allowed to rest for two minutes, which was followed by another three minutes of mixing at a high speed of $195 \mathrm{rpm}$.

For cement pastes with DE replacement, cement powder and DE were first dry mixed for one minute with a low speed of $136 \mathrm{rpm}$. Then, the same mixing procedure used for control pastes was followed. Mixing and all following tests were conducted at $25{ }^{\circ} \mathrm{C}$.

\subsection{Rheological and mini-cone slump tests}

The rheometer (Model: Anton Paar MCR 502) with a co-cylindrical cup-and-bob configuration (gap size of $1.13 \mathrm{~mm}$ ) was used to measure the rheological properties of all pastes. For more information on the geometry of the co-cylindrical configuration see Figure 1 and Table 4. During the tests, the cement pastes were first pre-sheared at a shear rate of $600 \mathrm{~s}^{-1}$ for ten seconds to minimize the effects of shear history during mixing, so that all the samples can start from the same reference point. The paste then rested for three minutes. After that, samples were sheared based on a descending flow curve at six different shear rates $\left(300,250,200,150,100\right.$, and $50 \mathrm{~s}^{-}$ $\left.{ }^{1}\right)$. Samples were maintained at each shear rate for ten seconds and the corresponding shear 
stresses were measured. The Bingham model was applied to calculate the viscosity and the yield stress.
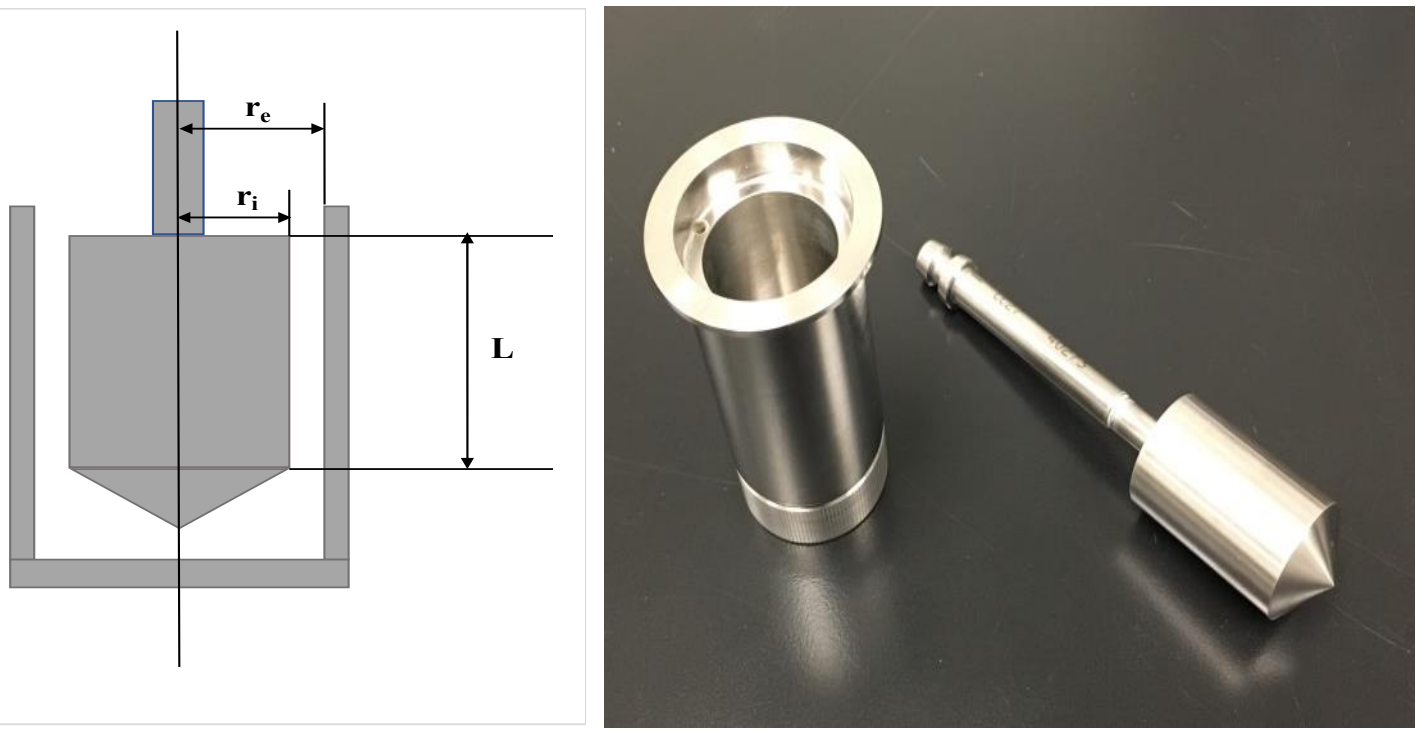

Fig 1. Concentric geometry

Table 4. Geometrical parameters of concentric cylinders

\begin{tabular}{|c|c|}
\hline Geometrical parameters & Co-cylindrical configuration \\
\hline \hline Gap size $\left(\mathrm{r}_{\mathrm{e}}-\mathrm{r}_{\mathrm{i}}\right)$ & $1.130 \mathrm{~mm}$ \\
\hline $\mathrm{r}_{\mathrm{e}}$ & $14.460 \mathrm{~mm}$ \\
\hline $\mathrm{r}_{\mathrm{i}}$ & $13.330 \mathrm{~mm}$ \\
\hline $\mathrm{L}$ & $39.997 \mathrm{~mm}$ \\
\hline Cone angle & $120^{\circ}$ \\
\hline
\end{tabular}

Previous studies showed that concrete flows during mixing and pumping can correspond to different shear rate. During mixing and casting, concrete may experiences shear rates of up to 60 $\mathrm{s}^{-1}$ (Roussel, 2006). However, during pumping, especially high speed pumping, cement paste can be subjected to much higher shear rates especially at the lubricating layer, from $217 \mathrm{~s}^{-1}$ up to $924 \mathrm{~s}^{-1}$ (Kim et al., 2017). Therefore, in this study, $300 \mathrm{~s}^{-1}$ was used as the maximum shear rate applied to the pastes.

The mini-cone slump tests were also conducted for all the paste samples to measure the flow diameter. The average of the flow diameter in two perpendicular directions was used to represent the flow diameter of the corresponding cement paste.

All Rheological and mini-cone slump tests were conducted 12 minutes after initial mixing.

\subsection{Bleeding test}

After mixing, the pastes were poured within $0.6 \mathrm{~cm} \mathrm{(1/4} \mathrm{inch)} \mathrm{from} \mathrm{the} \mathrm{top} \mathrm{of} \mathrm{the} 5 \mathrm{~cm}(2$ inches) by $10 \mathrm{~cm}$ (4 inches) cylinders and then weighed. The containers were capped after weighing to prevent moisture loss. After 30 minutes elapsed, the cylinders were tilted $30^{\circ}$ from vertical and bleed water was removed with a transfer pipette. Caution was taken to prevent removing any of the paste with the bleed water. Once no more visible bleed water remained on the surface, the cylinders were weighed and capped with a plastic lid. This process was repeated every 30 minutes until no further bleed water was observed. The reported value of weight loss and the weight loss rate is the averages of the three specimens (Sun \& Young, 2014). 


\subsection{Setting time}

The initial and final setting time of all cement pastes were determined by the Vicat needle tests, which were carried out according to ASTM C191 (2008). When the needle penetrated the cement paste for $25 \mathrm{~mm}$, the initial set was achieved. Final setting was attained when there was no mark of the specimen surface with a complete circular impression (Liu et al., 2014).

\subsection{Isothermal calorimetry}

The heat of hydration of all cement pastes was measured by the isothermal calorimetric test as defined by ASTM C1702 (2009). TAM Air, a commercial calorimeter, was adopted in this study. It was an eight-channel isothermal heat conduction calorimeter with the operating temperature range between $5^{\circ} \mathrm{C}$ and $60^{\circ} \mathrm{C}$. Before testing, the equipment was carefully calibrated based on the calibration procedures specified by the manufacturer. The energy change during hydration was collected and registered by an automated data acquisition program. The energy value was calculated based on the unit weight of the cementitious materials' mass.

\section{Results and discussion}

\subsection{Rheological and slump tests}

Viscosity and yield stress of all different cement pastes were calculated based on the obtained flow curves and using the Bingham model (Banfill, 2003). Figures 2 and 3 show the calculated viscosity and yield stress, respectively.

It can be seen clearly that by increasing the DE replacement level, the viscosity is increased for all the $\mathrm{w} / \mathrm{b}$ ratios. The rheological properties of cement paste are highly related to its interparticle and non-contact surface forces (van der Waals, double layer) (Lootens et al., 2004; Banfill, 1990). DE particles, due to their high Blaine surface and porous structure, tend to absorb the free water available in the paste. Although this water will be released back to the cement matrix in later ages, in the early age, it causes a reduction in water content. It should also be noticed that the specific gravity of DE is lighter than cement. When cement is replaced by DE with the same mass, the solid volume fraction increases. The increased solid volume fraction together with the porous texture of DE result in higher inter-particle interactions and consequently higher viscosity.

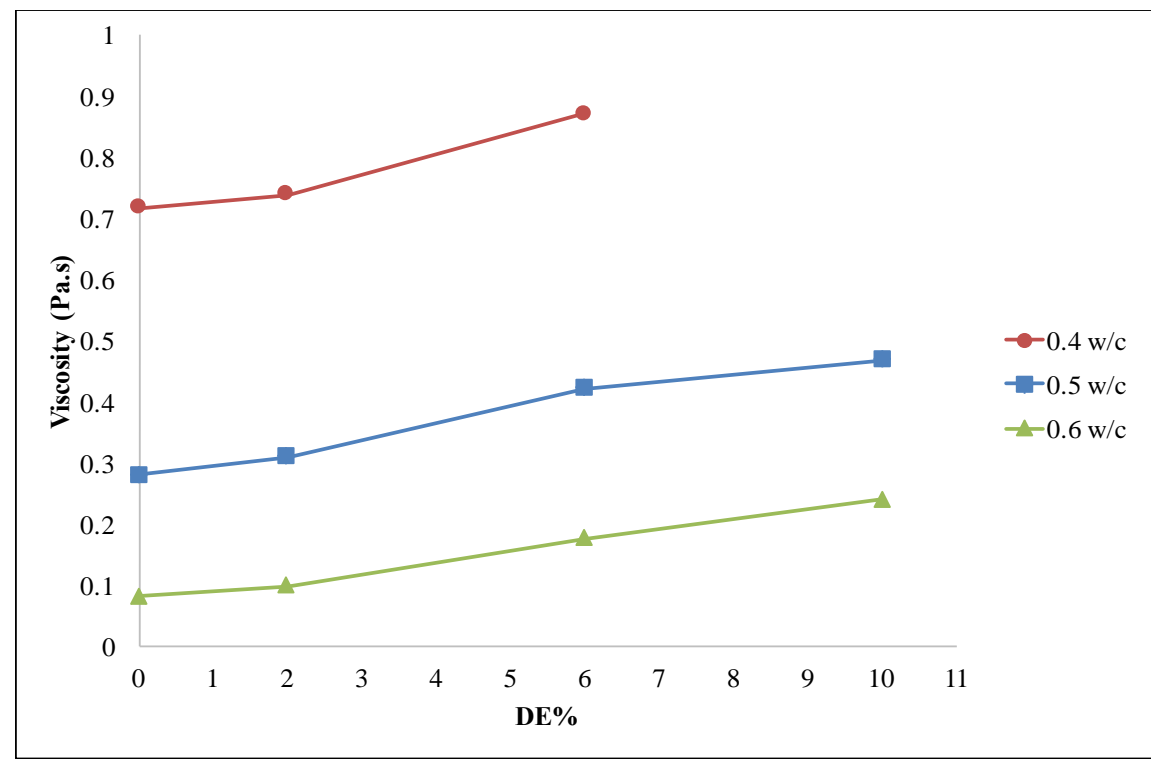

Fig 2. Viscosity of cement pastes against DE replacement levels 


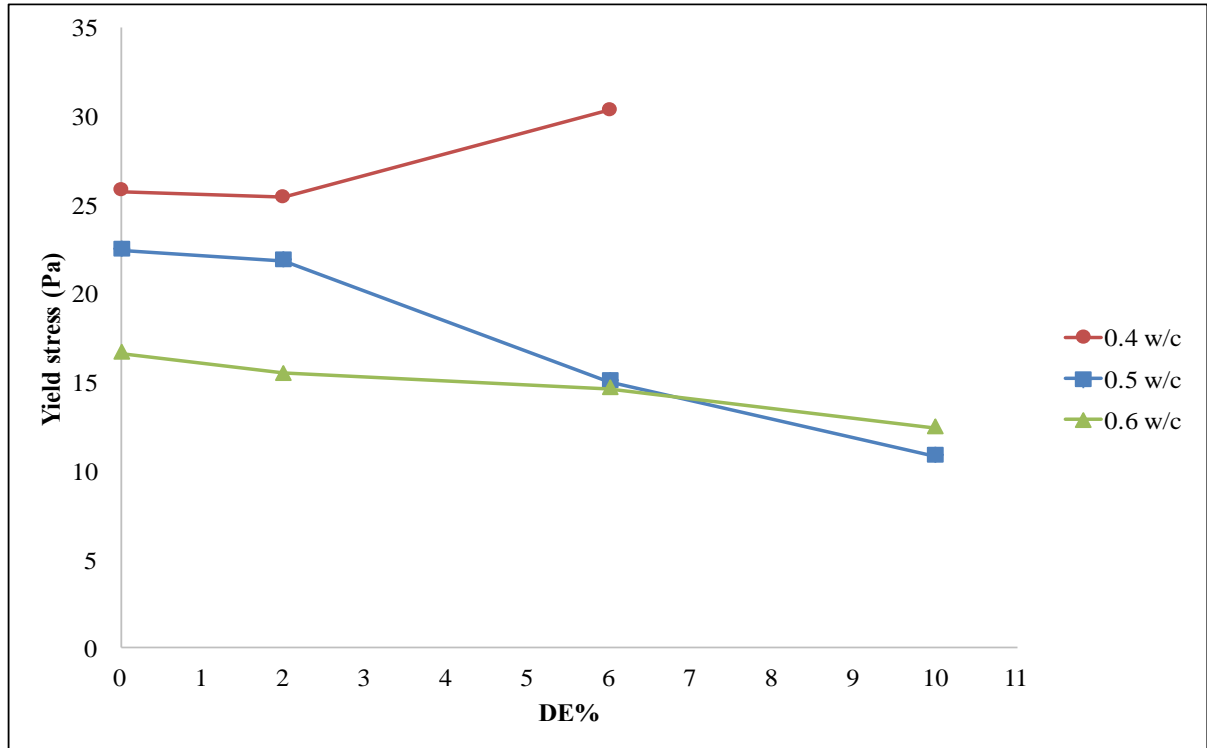

Fig 3. Yield stress of cement pastes against DE replacement levels

Table 5 lists the solid volume fraction of each mix proportion.

Table 5. Solid volume fraction of different mix proportions (cement density $=3.15 \mathrm{~g} / \mathrm{cm}^{3}, \mathrm{DE}$ density $=2.3$ $\mathrm{g} / \mathrm{cm}^{3}$ and DE absorption capacity $=1.5$ times its own weight

\begin{tabular}{|c|c|}
\hline Cement paste & Solid volume fraction \\
\hline \hline OPC-0.4 & 0.44 \\
\hline D2-0.4 & 0.46 \\
\hline D6-0.4 & 0.51 \\
\hline OPC-0.5 & 0.39 \\
\hline D2-0.5 & 0.40 \\
\hline D6-0.5 & 0.44 \\
\hline D10-0.5 & 0.48 \\
\hline OPC-0.6 & 0.35 \\
\hline D2-0.6 & 0.36 \\
\hline D6-0.6 & 0.39 \\
\hline D10-0.6 & 0.42 \\
\hline
\end{tabular}

Figure 3 depicts changes in yield stress by different replacement levels of DE. It shows that for 0.5 and $0.6 \mathrm{w} / \mathrm{b}$ ratios, increasing the DE replacement level in cement pastes constantly leads to a drop in yield stress. However, for $0.4 \mathrm{w} / \mathrm{b}$ ratio, increasing the replacement level at first does not change the yield stress significantly (it drops slightly from $25.75 \mathrm{~Pa}$ for OPC-0.4 to $25.42 \mathrm{~Pa}$ for D2-0.4). While after that point, by increasing the DE content from $2 \%$ to $6 \%$, the yield stress increases considerably (from 25.42 Pa for D2-0.4 to $30.32 \mathrm{~Pa}$ for D6-0.4).

To explain these changes in the yield stress of cement pastes with different $\mathrm{w} / \mathrm{b}$ ratios and different DE replacement levels, the change in their shear behaviors should be considered. Shear thinning and shear thickening are typical for non-Newtonian flow fluids, in which viscosity nonlinearly decreases or increases by an increase in shear rate (He et al., 2015; Yahia, 2014). Shearthinning is generally attributed to shear-induced deflocculation while shear-thickening is generally attributed to repulsive interactions between both colloidal and non-colloidal particles in the case of suspensions (Bouras et al, 2012).

Figure 4 and Figure 5 show the flow curves of cement pastes with a water to binder ratio of 0.6 and 0.4 , respectively $(0.5 \mathrm{w} / \mathrm{b}$ ratios had very similar flow curves as of 0.6$)$. 


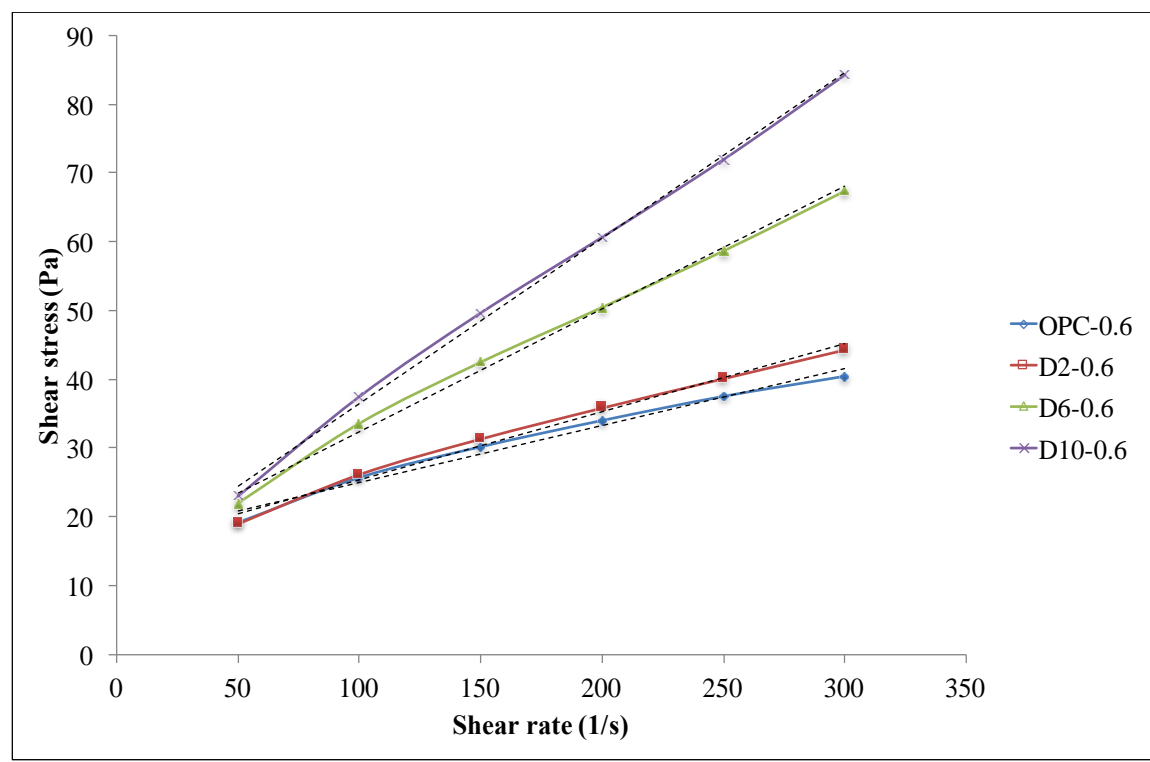

Fig 4. Flow curve of cement pastes with $0.6 \mathrm{w} / \mathrm{b}$ ratio

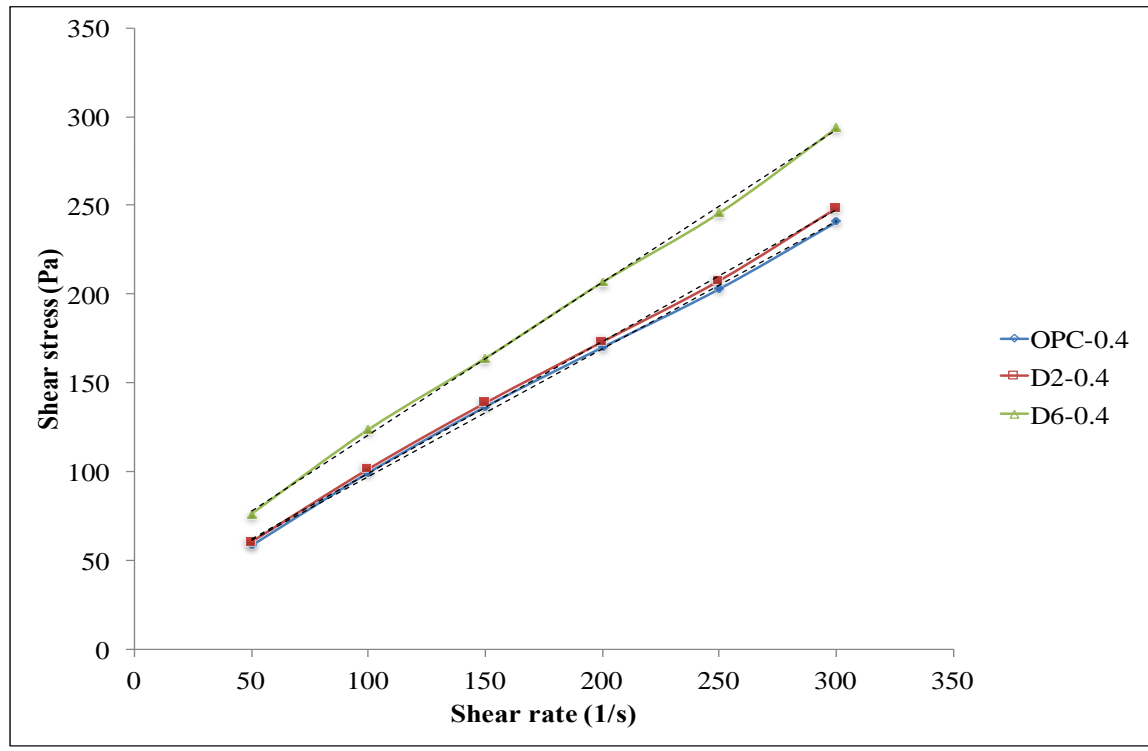

Fig 5. Flow curve of cement pastes with $0.4 \mathrm{w} / \mathrm{b}$ ratio

It can be seen that the control cement paste (OPC-0.6) with no additive shows a clear shear thinning behavior all along its flow curve while OPC-0.4 first shows shear thinning at low shear rates and then shear thickening behavior at higher shear rates. This is in agreement with the findings of previous research which showed cement pastes with lower w/c ratios show more shear thickening behavior than pastes with higher w/c ratios at high shear rates (Yahia, 2011). Also, one can easily see that by increasing the DE replacement level, flow curves from both w/b ratios (0.6 and 0.4) show more shear thickening behavior at higher shear rates. This can be explained by the porous structure and the high Blaine surface of the DE particles. According to $\mathrm{He}$ et al. (2015), the surface characteristics of dispersed particles significantly affect the rheological properties of the shear thickening fluids (STFs). They found that by dispersing porous particles (like porous silica fume) in polar liquids, the high specific surface areas and rough surface nature of the porous particles may influence the interfacial interaction between particles and dispersing medium to improve shear thickening behavior (He et al., 2015). 
From Figure 4, it can also be seen that using DE to partially replace cement not only changes the flow behavior from shear thinning to shear thickening at a high shear rate but also the higher the DE dosage, the more obvious this transition would be.

The flow diameter of cement pastes with different $\mathrm{w} / \mathrm{c}$ ratios and DE replacement levels are shown in Figure 6. Results show a consistent decrease in flow diameter by increasing the DE content. This can be explained by a high Blaine surface, porous structure, and the waterabsorbent nature of DE particles that leads to lower water content in cement pastes. According to previous studies (Ferraris et al., 2001; Wallevik, 2006), there is a correlation between minislump flow diameter and yield stress. A lower yield stress corresponds to a higher spread in the minislump (Ferraris et al., 2001). However, this research shows the slump flow can be related to both viscosity and yield stress. For the pastes with DE replacement, the viscosity may dominate the flow diameter.

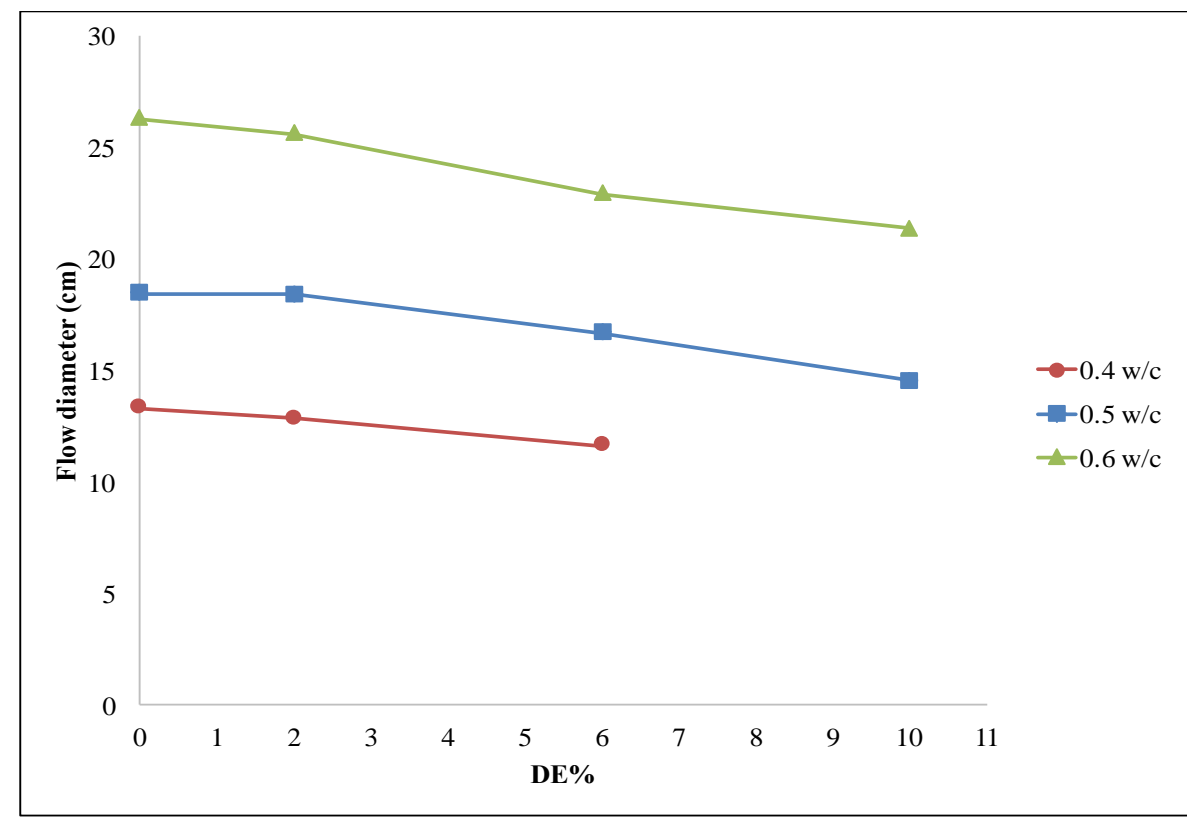

Fig 6. Flow dia meter of cement pastes against DE replacement levels

It should be noted that paste D10-0.4 has very poor workability. Due to its high water demand (Miller et al., 2010; Degirmenci \& Yilmaz, 2009; Fragoulis et al., 2005; Stamatakis et al., 2003; Yllmaz \& Ediz, 2008; Agullo et al., 1999), implementing rheological and mini-cone slump tests were not feasible for this cement paste.

\subsection{Bleeding test}

Figure 7 plots the changes in weight loss due to bleeding against time. As it is clear from this figure, for pastes with $0.4 \mathrm{w} / \mathrm{b}$ ratio, by increasing the replacement level of the DE in cement paste, the weight loss decreases for all time intervals. However, for 0.5 and 0.6 pastes, no clear pattern is observed.

In the case of $0.4 \mathrm{w} / \mathrm{b}$ ratio, the bleeding water could be clearly identified and removed from the top of the specimen. While in 0.5 and $0.6 \mathrm{w} / \mathrm{b}$, it is hard to differentiate the bleeding water and the diluted paste layer. Some cement particles may be accidentally removed together with the water when the pipette was used. Therefore, the trend line plotted with higher $\mathrm{w} / \mathrm{b}$ ratios probably contains higher measurement errors. Hence, the focus of the data analysis on bleeding will be on the $0.4 \mathrm{w} / \mathrm{b}$ pastes. 


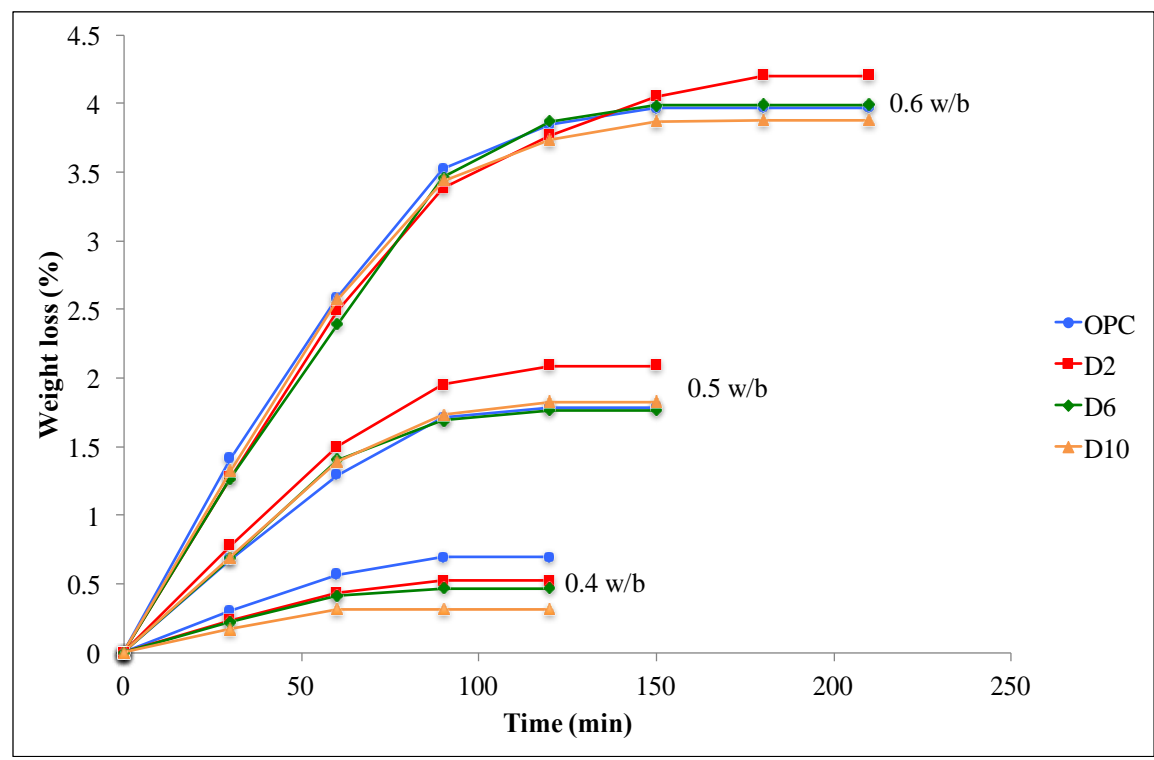

Fig 7. Weight loss of cement pastes against time

Figure 8 plots the changes in bleeding rates for all the pastes with $\mathrm{w} / \mathrm{b}$ ratio of 0.4 . One can see that for a given age, e.g. 30 minutes after mixing, the control specimen has the highest bleeding rate, and the rate decreases accordingly with the increase in DE replacement. This indicates that adding DE to cement paste can delay and reduce bleeding effectively. From the figure, it can also be noticed that bleeding for the D10-0.4 paste stopped earlier than any other pastes. This is another indication of minimizing the bleeding effect by using DE.

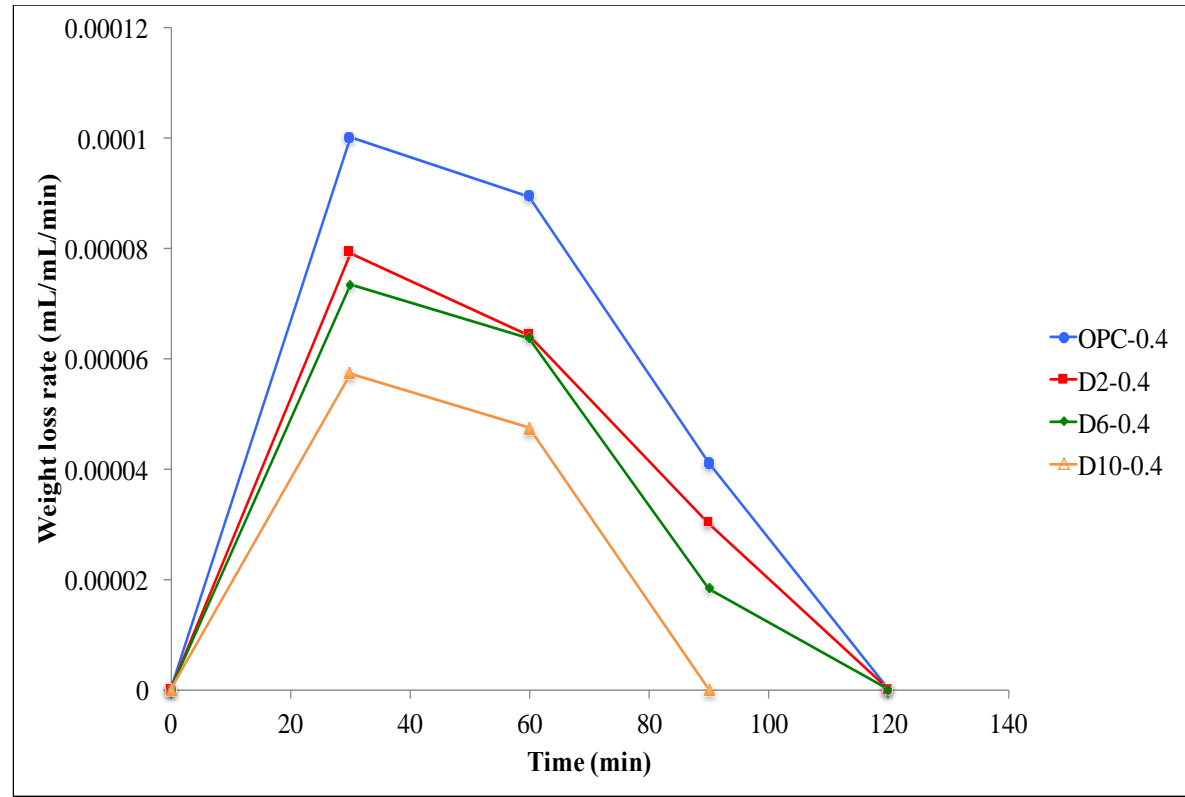

Fig 8. Weight loss rate of cement pastes against time for $0.4 \mathrm{w} / \mathrm{b}$ ratio, weight loss rate $=\left(w_{t 1}-w_{t 2}\right) / w_{t 1} /\left(t_{1}-t_{2}\right)$

\subsection{Setting time}

Initial and final setting time of all cement pastes with different water to binder ratios and DE replacement levels are provided in Table 6.

It is observed that for all the $\mathrm{w} / \mathrm{b}$ ratios that were studied, increasing the DE replacement levels causes decreases in both initial and final setting times, it also shortens the time difference between the initial and final settings for all the 0.4 and 0.5 pastes. 
Table 6. Initial and final setting of cement pastes with different $w / c$ ratios and DE replacement levels

\begin{tabular}{|c|c|c|}
\hline Cement paste & initial set (min) & final set (min) \\
\hline OPC-0.4 & 226 & 350 \\
\hline D2-0.4 & 178 & 310 \\
\hline D6-0.4 & 166 & 255 \\
\hline D10-0.4 & 141 & 240 \\
\hline OPC-0.5 & 268 & 450 \\
\hline D2-0.5 & 246 & 390 \\
\hline D6-0.5 & 234 & 375 \\
\hline D10-0.5 & 229 & 360 \\
\hline OPC-0.6 & 340 & 570 \\
\hline D2-0.6 & 328 & 565 \\
\hline D6-0.6 & 300 & 555 \\
\hline D10-0.6 & 275 & 535 \\
\hline
\end{tabular}

Also, among cement pastes with the same DE content, those with a higher $\mathrm{w} / \mathrm{c}$ ratio have a longer initial and final setting time as expected. In addition, in cement pastes with lower $\mathrm{w} / \mathrm{b}$ ratios, the rate of reduction in setting time (final setting) by increasing the DE content is much higher than those with higher w/b ratios. For example, it took 110 minutes less for D10-0.4 to reach final set compared to OPC-0.4, however, the final setting time has only been shortened by 35 minutes for 0.6 pastes when $10 \%$ of the cement is replaced by DE.

Replacing cement with DE reduces the concentration of cement particles in cement paste (i.e. reduces cement content) and is expected to prolong setting time. But on the other hand, DE particles due to their porous structure and high Blaine surface, can absorb some of the free water in the paste that lowers the free water content and improves diffusion of water in the cement matrix which shortens the time for water to reach the non-hydrated cement..

\subsection{Isothermal calorimetry}

For all water to binder ratios, increasing the DE content reduced the heat evolution of cement pastes on the first 70 hours. As an example, the heat evolution of pastes with $0.4 \mathrm{w} / \mathrm{b}$ ratio at different DE replacement levels are shown in Figure 9.

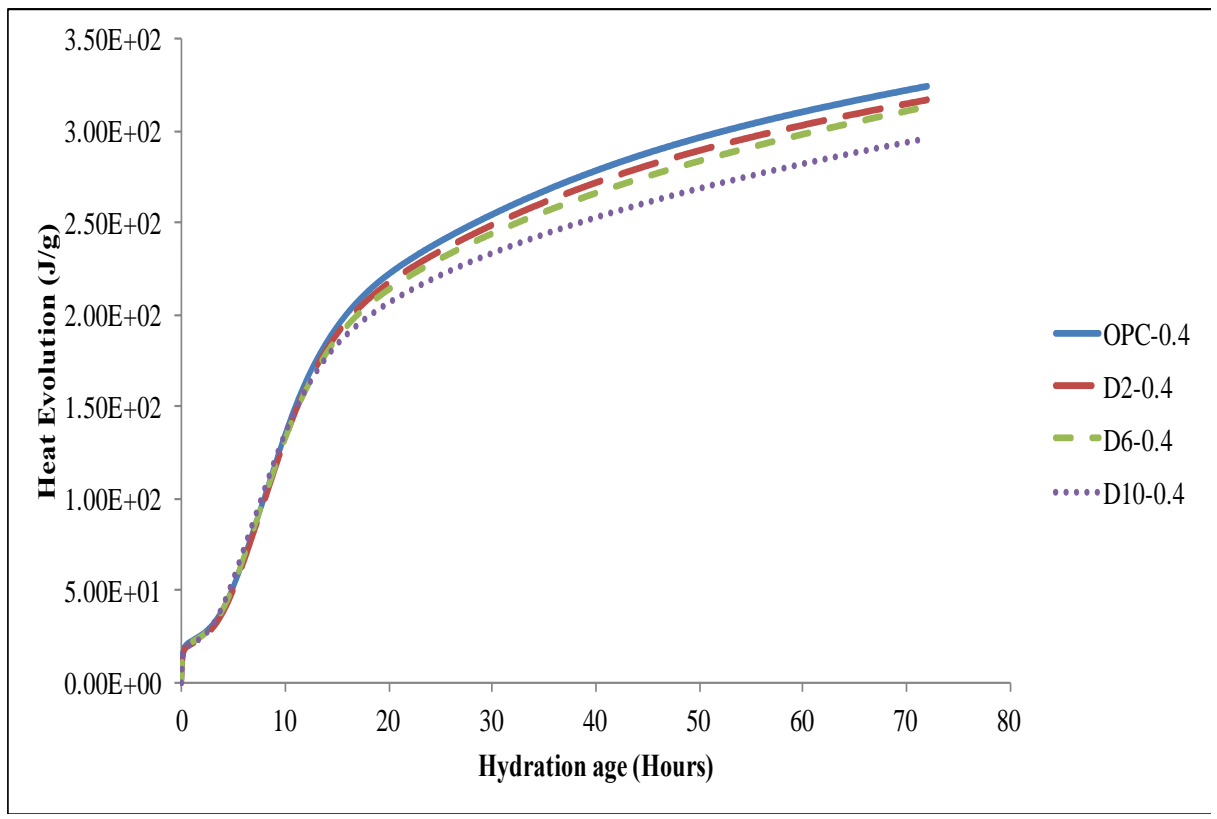

Fig 9. Heat evolution of cement pastes with $0.4 \mathrm{w} / \mathrm{b}$ ratio 
Figures 10 to 12 show the rate of heat evolution of all the cement pastes against time. It should be pointed out that these figures are cut and enlarged from hydration age 0.5 to 20 hours for better illustration of changes in peaks of heat evolution rate. The first peak in the figure is mainly associated with the hydration of $\mathrm{C}_{3} \mathrm{~S}$ in cement paste and the second peak is mostly attributed to the hydration of $\mathrm{C}_{3} \mathrm{~A}$ (Rahhal \& Talero, 2009; Pang et al., 2013; Mostafa \& Brown, 2005). It is clear from these figures that an increase in DE content results in a drop in the heat evolution rate of both peaks for all $\mathrm{w} / \mathrm{b}$ ratios. As mentioned in the previous section, this is simply due to the decrease in clinker phases (cement content), which is caused by replacing cement with DE.

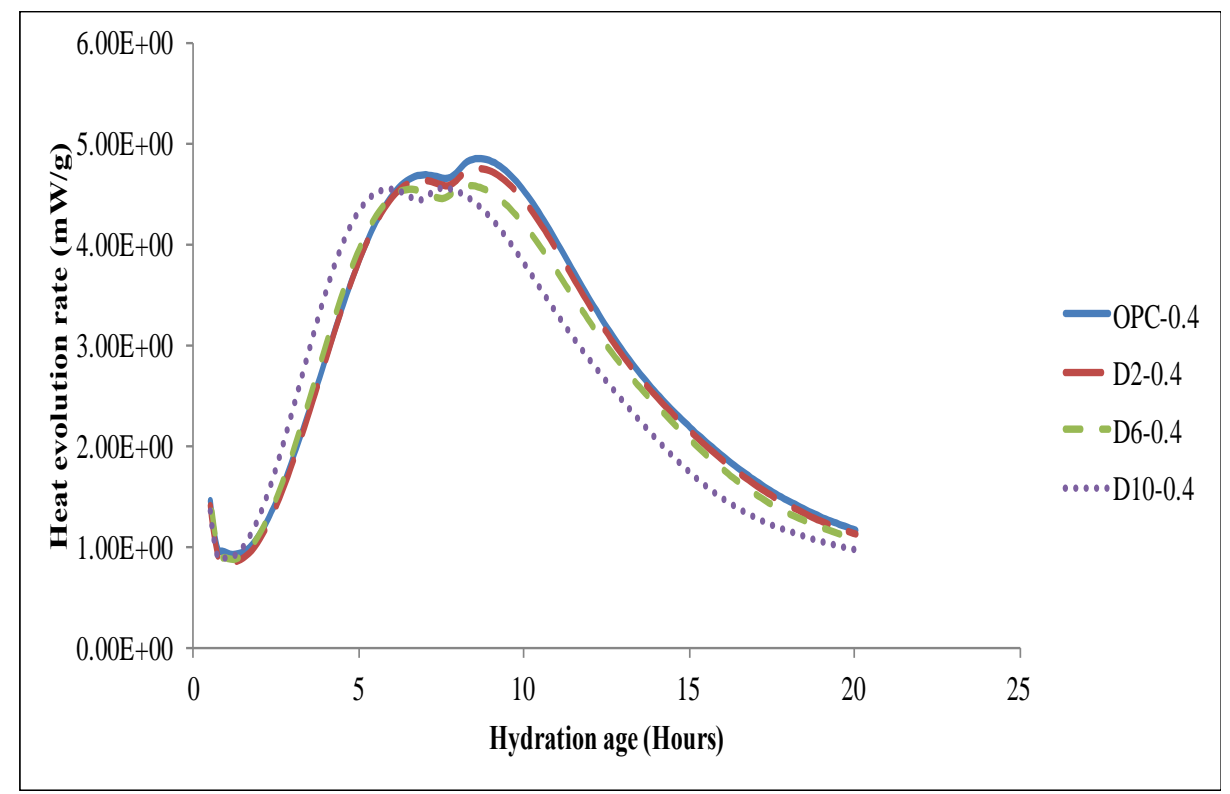

Fig 10. Heat evolution rate of cement pastes with $0.4 \mathrm{w} / \mathrm{b}$ ratio

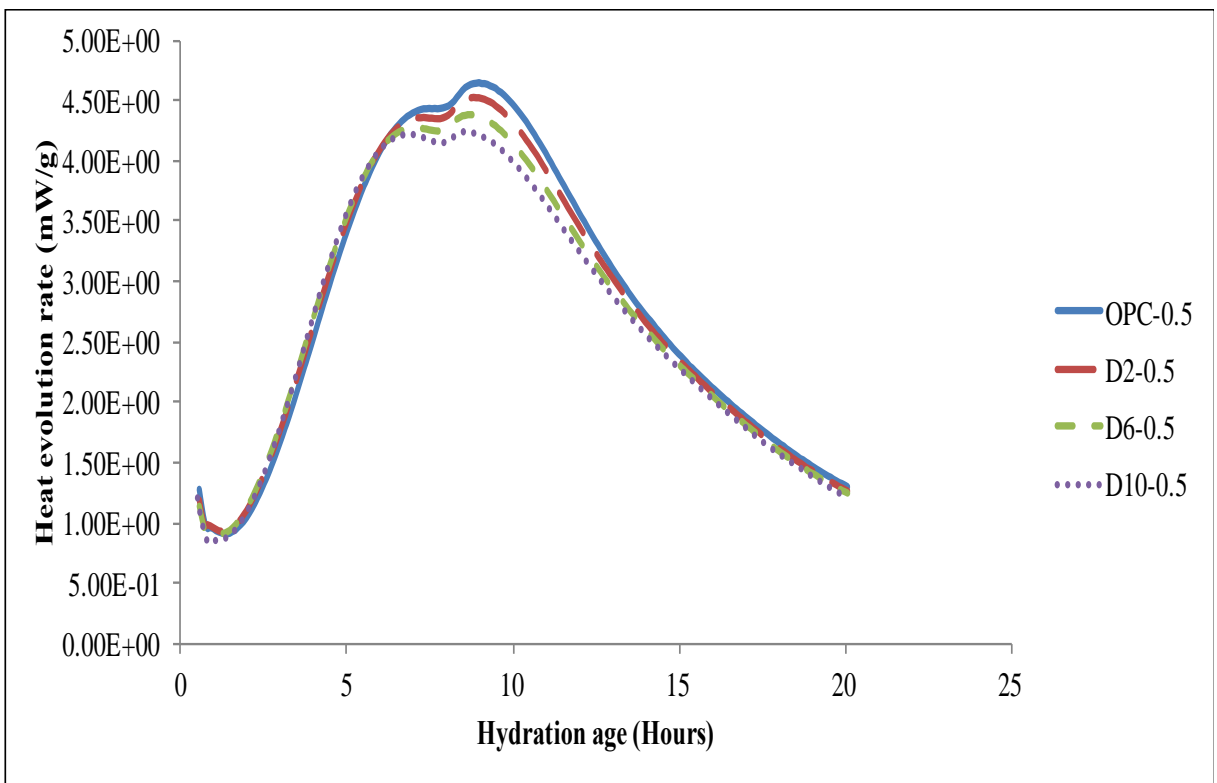

Fig 11. Heat evolution rate of cement pastes with $0.5 \mathrm{w} / \mathrm{b}$ ratio 


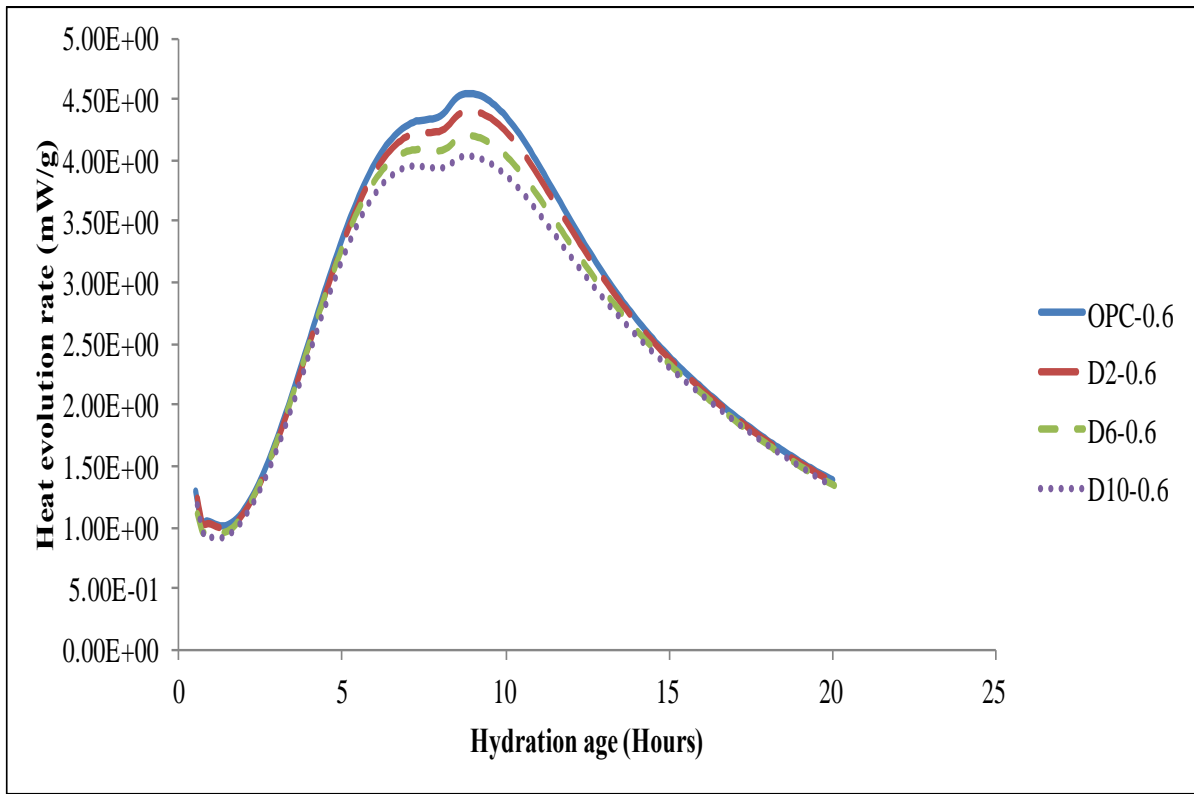

Fig 12. Heat evolution rate of cement pastes with $0.6 \mathrm{w} / \mathrm{b}$ ratio

In addition, for all water to binder ratios, higher DE content led to shifts (to the left) for both peaks. The higher the DE content the larger the shift is (Table 7). Also, the shift with an increase in $\mathrm{DE}$ content is observed to be more obvious for cement pastes with lower $\mathrm{w} / \mathrm{b}$ ratios.

Table 7. Hydration age of first and second peaks of heat evolution rate for all cement pastes

\begin{tabular}{|c|c|c|}
\hline Cement paste & first peak $(\mathrm{h})$ & second peak $(\mathrm{h})$ \\
\hline \hline OPC-0.4 & $\mathbf{7 . 0 2 6 7 6}$ & $\mathbf{8 . 6 9 3 4 3}$ \\
\hline D2-0.4 & -0.08975 & -0.08976 \\
\hline D6-0.4 & -0.43464 & -0.35131 \\
\hline D10-0.4 & -1.09506 & -1.09506 \\
\hline OPC-0.5 & $\mathbf{7 . 8 8 2 6 1}$ & $\mathbf{8 . 9 6 5 9 4}$ \\
\hline D2-0.5 & -0.48359 & -0.15025 \\
\hline D6-0.5 & -0.81736 & -0.23402 \\
\hline D10-0.5 & -0.96151 & -0.29484 \\
\hline OPC-0.6 & $\mathbf{7 . 9 3 6 2 8}$ & $\mathbf{9 . 0 1 9 6 1}$ \\
\hline D2-0.6 & -0.23428 & -0.15094 \\
\hline D6-0.6 & -0.52509 & -0.19175 \\
\hline D10-0.6 & -0.72741 & -0.22741 \\
\hline
\end{tabular}

These results fully support discussion in the previous section and research findings from the setting time test. The acceleration of peak appearance can be attributed to the absorption of free water to DE particles that cause the increase of the solution of cement clinkers (like $\mathrm{C}_{3} \mathrm{~A}$ ) in water. This leads to the higher solubility of ions such as $\mathrm{Ca}^{2+}$ (i.e. higher zeta potential). It, in turn, accelerates the formation of hydration products and shortens the setting time (Yllmaz \& Ediz, 2008; Nägele, 1985; Plank \& Hirsch, 2007). Kastis et al. (2006) pointed out that the pozzolanic nature of diatomite can form higher amounts of hydration products in the paste. Based on the findings of Rahhal and Talero (2009), the hydration reactions may be stimulated by the positive and negative electrostatic charge acquired by the particles of pozzolans during mixing, and subsequently, by the zeta potential specially originated as Portland cement hydration progresses (Wallevik, 2006). Therefore, DE particles could play the role as nucleation sites (like seed crystals) for calcium hydroxide crystals to precipitate with accelerated setting (Rahhal and Talero, 2009). Putting Figures 10-12 together with Table 6, one can see that the earlier the peaks appear, the quicker the paste would set. 


\section{Conclusion}

Findings of this paper show that using Diatomaceous Earth (DE) as a partial replacement for cement has a significant influence on the fresh properties of cement pastes. The porous shape and high Blaine surface of DE particles make this natural pozzolanic additive of cement pastes highly water absorbent. DE can impact fresh properties of cement pastes as follows:

- Increase in DE content of cement pastes increased the apparent viscosity of cement pastes with $\mathrm{w} / \mathrm{b}$ ratios of $0.4,0.5$, and 0.6 . It can be due to the higher solid volume fraction of cement pastes with higher DE content which leads to higher inter-particle interactions.

- Increase in DE content changed the shear behavior of cement pastes from shear thinning to shear thickening behavior. This change in shear behavior is clearer in cement pastes with 0.5 and $0.6 \mathrm{w} / \mathrm{b}$ ratios.

- Increase in DE content decreased the flow diameter of cement pastes at all water to binder ratios.

- Increase in DE content of cement pastes reduced the bleeding rate of cement pastes with $0.4 \mathrm{w} / \mathrm{b}$ ratio.

- Increase in DE content shortened both the initial and final setting times of cement pastes at all $\mathrm{w} / \mathrm{b}$ ratios. DE particles improve water diffusion, increase zeta potential, and accelerate the formation of hydration products which lead to shorter setting times.

- Increase in DE content lowers the hydration heat of cement pastes at all water to binder ratios due to the lower cement content of cement pastes.

- Results from isothermal calorimetry show that an increase in the replacement level of cement with DE hastens the hydration process in cement pastes with all water to cement ratios which is in good agreement with results from setting time test.

\section{Acknowledgements}

The financial support from the National Science Foundation (CMMI-1265983, CMMI-1413031), Kentucky Science and Engineering Foundation (KSEF-3242-RDE-018) and the Department of Civil and Environmental Engineering at the University of Louisville, are highly appreciated. The authors also appreciate the Cemex Technical Center for cement chemical composition analysis.

\section{References}

Agullo, L., Toralles-Carbonari, B., Gettu, R., \& Aguado, A. (1999). Fluidity of cement pastes with mineral admixtures and superplasticizer-a study based on the Marsh cone test. Materials and Structures, 32(7), 479-485.

ASTM C1702. (2009). Standard test method for measurement of heat of hydration of hydraulic cementitious materials using isothermal conduction calorimetry. ASTM International West Conshohocken, Pa.

ASTM C191. (2008). Standard Test Method for Time of Setting of Hydraulic Cement by Vicat Needle. ASTM International West Conshohocken, Pa.

Aydin, A. C., \& Gül, R. (2007). Influence of volcanic originated natural materials as additives on the setting time and some mechanical properties of concrete. Construction and building materials, 21(6), 1277-1281.

Bakr, H. E. G. M. M. (2010). Diatomite: its characterization, modifications and applications. Asian journal of materials science, 2(3), 121-136. 
Banfill, P. (1990). Rheology of Fresh Cement and Concrete: Proceedings of an International Conference, Liverpool, CRC Press.

Banfill, P. (2003). The rheology of fresh cement and concrete - A review. In International Cement Chemistry Congress. Durban.

Bouras, R., Kaci, A., \& Chaouche, M. (2012). Influence of viscosity modifying admixtures on the rheological behavior of cement and mortar pastes. Korea-Australia Rheology Journal, 24(1), 35-44.

Degirmenci, N., \& Yilmaz, A. (2009). Use of diatomite as partial replacement for Portland cement in cement mortars. Construction and Building Materials, 23(1), 284-288.

Dolley, P. (1999). Diatomite: Minerals Yearbook: Volume I-Metals and Minerals. US Geological Survey, p. 1-4.

Ergün, A. (2011). Effects of the usage of diatomite and waste marble powder as partial replacement of cement on the mechanical properties of concrete. Construction and building materials, 25(2), 806812.

Ferraris, C. F., Obla, K. H., \& Hill, R. (2001). The influence of mineral admixtures on the rheology of cement paste and concrete. Cement and concrete research, 31(2), 245-255.

Fragoulis, D., Stamatakis, M. G., Papageorgiou, D., \& Chaniotakis, E. (2005). The physical and mechanical properties of composite cements manufactured with calcareous and clayey Greek diatomite mixtures. Cement and Concrete Composites, 27(2), 205-209.

He, Q., Gong, X., Xuan, S., Jiang, W., \& Chen, Q. (2015). Shear thickening of suspensions of porous silica nanoparticles. Journal of materials science, 50(18), 6041-6049.

Jewell, S. \& Kimball, S.M. (2015). MINERAL COMMODITY SUMMARIES 2015, in annual U.S. Geological Survey.

Jewell, S., \& Kimball S.M. (2016). MINERAL COMMODITY SUMMARIES 2016, in annual U.S. Geological Survey: USGS.

Jud Sierra, E., Miller, S. A., Sakulich, A. R., MacKenzie, K., \& Barsoum, M. W. (2010). Pozzolanic activity of diatomaceous earth. Journal of the American Ceramic Society, 93(10), 3406-3410.

Kastis, D., Kakali, G., Tsivilis, S., \& Stamatakis, M. G. (2006). Properties and hydration of blended cements with calcareous diatomite. Cement and concrete research, 36(10), 1821-1826.

Kim, J. H., Kwon, S. H., Kawashima, S., \& Yim, H. J. (2017). Rheology of cement paste under high pressure. Cement and Concrete Composites, 77, 60-67.

Liu, F., Sun, Z., \& Qi, C. (2014). Raman spectroscopy study on the hydration behaviors of Portland cement pastes during setting. Journal of Materials in Civil Engineering, 27(8), 04014223.

Lootens, D., Hébraud, P., Lécolier, E., \& Van Damme, H. (2004). Gelation, shear-thinning and shearthickening in cement slurries. Oil \& gas science and technology, 59(1), 31-40.

Miller, S. A., Sakulich, A. R., Barsoum, M. W., \& Jud Sierra, E. (2010). Diatomaceous Earth as a Pozzolan in the Fabrication of an Alkali-Activated Fine-Aggregate Limestone Concrete. Journal of the American Ceramic Society, 93(9), 2828-2836.

Mostafa, N. Y., \& Brown, P. W. (2005). Heat of hydration of high reactive pozzolans in blended cements: isothermal conduction calorimetry. Thermochimica acta, 435(2), 162-167.

Nägele, E. (1985). The zeta-potential of cement. Cement and Concrete Research, 15(3), 453-462.

Pang, X., Bentz, D. P., Meyer, C., Funkhouser, G. P., \& Darbe, R. (2013). A comparison study of Portland cement hydration kinetics as measured by chemical shrinkage and isothermal calorimetry. Cement and Concrete Composites, 39, 23-32.

Plank, J., \& Hirsch, C. (2007). Impact of zeta potential of early cement hydration phases on superplasticizer adsorption. Cement and concrete research, 37(4), 537-542.

Rahhal, V., \& Talero, R. (2009). Calorimetry of Portland cement with silica fume, diatomite and quartz additions. Construction and Building Materials, 23(11), 3367-3374. 
Robert, D. Crangle, J. (2013) DIATOMITE, Mineral Yearbook 2013, in annual. U.S. Geological Survey: Mineral Yearbook. p. 22.1-22.5.

Roussel, N. (2006). A thixotropy model for fresh fluid concretes: theory, validation and applications. Cement and Concrete Research, 36(10), 1797-1806.

Stamatakis, M. G., Fragoulis, D., Csirik, G., Bedelean, I., \& Pedersen, S. (2003). The influence of biogenic micro-silica-rich rocks on the properties of blended cements. Cement and Concrete Composites, 25(2), 177-184.

Sun, Z., \& Young, C. (2014). Bleeding of SCC pastes with fly ash and GGBFS replacement. Journal of Sustainable Cement-Based Materials, 3(3-4), 220-229.

Taylor, H. F. (1997). Cement chemistry. Thomas Telford.

Wallevik, J. E. (2006). Relationship between the Bingham parameters and slump. Cement and Concrete Research, 36(7), 1214-1221.

Yahia, A. (2011). Shear-thickening behavior of high-performance cement grouts-Influencing mix-design parameters. Cement and concrete research, 41(3), 230-235.

Yahia, A. (2014). Effect of solid concentration and shear rate on shear-thickening response of highperformance cement suspensions. Construction and Building Materials, 53, 517-521.

Yılmaz, B., \& Ediz, N. (2008). The use of raw and calcined diatomite in cement production. Cement and Concrete Composites, 30(3), 202-211. 